\title{
Concurrent Carotid Endarterectomy and off-Pump Coronary Artery Bypass Graft Surgery in Bangladesh: a Prospective Cohort Study
}

\author{
*R Ranjan ${ }^{1}$, D Adhikary ${ }^{2}, \mathrm{H} \mathrm{Saha}^{3}$, SK Saha ${ }^{4}, \mathrm{~S} \mathrm{Mandal}^{5}, \mathrm{~K} \mathrm{Hasan}^{6}, \mathrm{AB}$ Adhikary${ }^{7}$
}

\begin{abstract}
Background: A patient of ischemic coronary artery disease (IHD) with additional carotid artery stenosis (CAS) has been distinguished as a high risk group for both heart and cerebral inconveniences following surgical intervention. We review the outcome of concurrent carotid endarterectomy (CEA) and off-pump coronary bypass grafting (OPCABG)in a patient undergoing surgical revascularization for IHD and CAS in a single surgeons practice.
\end{abstract}

Materials and Methods: In the vicinity of January 2012 and December2016, fifteen patients experienced OPCABG and CEA associatively in a single Surgeon's Practice. Majority $46.66 \%$ patient have $75-90 \%$ Carotid artery stenosis and 40\%patients experienced right sided lesion, though $53.33 \%$ experienced left sided lesion. $33.33 \%$ patients were found Left main coronary artery disease ( $>50 \%$ lesion) and $100 \%$ patients have had significant LAD lesion in this study. CEA was performed before OPCABG in all cases.

Result: Themean age was $62.5 \pm 2.8$ years; $80 \%$ were male. $13.33 \%$ had a perioperative stroke while one of them had TIAs (6.6\%). Mean ICU stay was 36.6 \pm 4.5 hours and patients were released in $10 \pm 2$ days. There was no mortality in the early postoperative period and co-morbidity was less significant; only $6.6 \%$ myocardial ischemia, $13.33 \%$ Atrial fibrillation, $6.66 \%$ TIA, and $13.33 \%$ Stroke.

Conclusion: A combined strategy by means of CEA with OPCABG is safe and savvy in view of the satisfactory consequences of morbidity and mortality rates and also short ICU and hospital stay status.

Key Words: Carotid artery stenosis (CAS), coronary artery disease (CAD), coronary artery bypass grafting, carotidendarterectomy

\section{Introduction}

Atherosclerosis is a systemic disease affecting large and medium-sized arteries in which plaque builds up inside the arteries causing thickening and hardening of arteries. Plaque is composed of cholesterol, fatty substances, cellular waste products, calcium and fibrin. Atherosclerotic plaque may partially or totally occlude the blood's flow through an artery in the heart, brain, pelvis, legs, arms or kidneys that may develop coronary heart disease, carotid artery disease, peripheral artery disease (PAD) and chronic kidney disease. ${ }^{1}$ Significant blockade ( $>70 \%$ stenosis) of coronary and carotid artery requires surgical intervention. The surgical options for coexisting CAD and CAS include concurrent carotid endarterectomy (CEA) and OPCABG or a sequential approach; two stage operation either CEA followed by OPCABG or OPCABG followed by CEA. Sequential or staged approach demonstrated low morbidity and mortality. Combined approach provides lower incidence of MI, stroke and death as

1Dr. Redoy Ranjan, Medical Officer, Department of Cardiac surgery, Bangabandhu Sheikh Mujib Medical University (BSMMU), Dhaka, Bangladesh

2Dr. Dipannita Adhikary, Assistant Surgeon, Al Helal Specialized Hospital

3 Dr. Heemel Saha, Assistant Surgeon, Al Helal Specialized Hospital

${ }^{4}$ Dr. Sanjoy Kumar Saha, Consultant, Department of Cardiac Anesthesia, Bangabandhu Sheikh Mujib Medical University

5Dr. Sabita Mandal, Associate Professor, Shaheed Suhrawardy Medical College, Dhaka

6Prof. Kamrul Hasan, Professor and Head of the Department of Cardiac Surgery, National Institute of Cardiovascular Disease (NICVD)

7Prof. Asit Baran Adhikary, Professor and Chairman, Department of Cardiac Surgery, Bangabandhu Sheikh Mujib Medical

University (BSMMU), Dhaka, Bangladesh

*Corresponding author

Date of submission: 12.06.2017, Date of acceptance: 23.10 .2017

AKMMC J 2018; 9(1) : 15-21 
well as cost effective using a single anesthetic and hospitalization. The signs and advantages of surgical revascularization of ischemic coronary or carotid artery disease are sufficiently clear ${ }^{1,2}$ though the most suitable surgical choice for concurrent coronary and carotid illness remains a subject of verbal confrontation. As indicated by studies in the writing, $8 \%-14 \%$ of coronary artery bypass grafting (CABG) patients have severe carotid artery stenosis $^{3,4}$ and $40 \%-50 \%$ of carotid endarterectomy (CEA) patients have coronary vascular disease5,6. Unfriendly neurologic occasions happened in $6.1 \%$ of elective CABG patients who had carotid artery stenosis correspondingly. ${ }^{7}$ In addition, when carotid artery surgery was performed in patients with symptomatic coronary artery disease, contemplates have proposed a rate of postoperative myocardial ischemic tissue of roughly $7 \%$, while its rate was $1 \%$ if the CEA was done in asymptomatic patients8,9. Subsequent to perceiving that total revascularization can be performed on the beating heart with partial aortic control, the prevalence of utilizing off-pump CABG (OPCABG) expanded in these concurrent coronary and carotid artery disease patients on account of their propensity to be at high hazard for perioperative unfriendly neurologic occasions when contrasted and the customary CABG strategy. ${ }^{10}$

However, till date there are no study regarding the outcome of concurrent CEA with OPCABG surgery in Bangladesh and we aimed to review the safety of concurrent OPCABG with CEA for critical coexistent coronary and carotid artery disease. Using this surgical approach for critical coexistent disease may minimize the incidence of perioperative cerebrovascular complications in patients undergoing OPCABG.

\section{Materials And Methods}

We explored the early line up information of 15 patients with concurrent carotid and coronary artery disease who experienced concurrent CEA with OPCABG in the vicinity of 2014 and 2016 in single Surgeon's Practice. Pre-operative, intra-operative, and early postoperative factors were gathered reflectively. Hypertension $(n=15,100 \%)$, smoking
Dyslipidemia $(n=12,80 \%)$ were the major atherosclerotic hazard variables. Six (40\%) patients had a heart history of myocardial dead tissue (MI), four $(26.66 \%)$ had unstable angina (USAP), and three $(20 \%)$ had USAP together with MI, though two $(13.33 \%)$ were asymptomatic. Nine (60\%) patients demonstrated no neurological manifestations, $3(20 \%)$ had transient ischemic assaults (TIAs), 2 (13.33\%) experienced stroke, and $1(6.66 \%)$ experienced both. Ipsilateral stenosis was $82.5 \pm 5.5 \%$ (Table 1); 5 patients had 50\%-75\%, 7 patients had $75 \%-90 \%$, and 3 patients had $>90 \%$ stenotic atherosclerotic carotid injuries. There were 5 patients with left main coronary artery disease.

\section{Surgical procedure}

\section{Carotid endarterectomy}

Carotid endarterectomy was done under general anesthesia3. Incision and proper exposure of the carotid bifurcation area followed by Systemic heparinization done before clamping the carotid artery (heparin $100 \mathrm{IU} / \mathrm{kg}$ ) to achieve ACT (activated clotting time) of 250-300s. Carotid endarterectomy was performed by a vertical cut foremost to the sternocleidomastoid muscle, consequently uncovering the normal, inner, and outer carotid conduit. The conduit was opened through a transverse cut to the distal part of the regular carotid supply route, trailed by an endarterectomywith preservation of internal jugular vein, and direct closure of arteriotomy technique was applied. The incision was closed in layers.

The eversion strategy of CEA was begun to be performed with the ICA through the plane between the external layers of media and the adventitia. The atheroma was pulled back and disconnected circumferentially while the external layer of the ICA was everted. The eversion advanced distally and delicate footing was utilized to totally evacuate the atheromatous plaque; then endarterectomy of the ECA and CCA was accomplished in a similar way. The neck wound was left open until the heparin was turned around by means of protamine after CABG. The injury was shut after CABG and switching the heparin, with or without seepage. The arteriotomy was shut specifically by consistent sutures without utilizing any kind of patches.

Routine duplex scan of carotid vessels done to 
screen the respective carotid supply route in both longitudinal and transverse planes was done as a major aspect of the preoperative assessment in all patients and it was trailed via carotid angiography in cases in which huge sickness was shown. Patients experiencing CEA had $\geqslant 50 \%$ carotid stenosis with one of the side effects of TIAs or ischemic stroke with a past filled with cerebral mishap or one-sided stenosis $\geqslant 75 \%$ with or with no indications.

\section{Technique of OPCABG}

Then a standard median sternotomy was performed. Then pericardiotomy was done and the proximal anastomosis of venous grafts was performed with partial aortic clamping. Heart was exposed and stabilized with the aid of a retractor and stabilizer. The targeted coronary artery was exposed. The artery was opened, and the distal anastomosis was fashioned. An intracoronary shunt was used to allow distal perfusion. On completion of that operation, protamine was given to restore the preoperative value of the activated clotting time. During surgery, blood pressure is lowered to approximately 60 or $70 \mathrm{mmHg}$ and the thinking has been that if pressure is reduced, the patient will be hemodynamically compromised and at an increased risk of stroke. Cardiovascular monitoring included continuous electrocardiographic monitoring during the first 72 hours. Routine standard biochemical and hematological profiles and repeat chest radiographs were also done. After operation, usually we kept patient in ICU for 36 hours and after that in ward till discharge.

\section{Results}

This study included 15 patients of CAS with CAD. The baseline characteristics of study population are given in the Table- I. It was observed that mean age was $62.5 \pm 2.8$ years and $80 \%$ patients were male. Majority (80\%) patients having history of Smoking and Dyslipidemia and almost all (100\%) patient have Hypertension. More than half $(60 \%)$ patients had Diabetes mellitus. Majority of the patient's had history of Ischemic heart disease (40\% MI, 26.66\% USAP, $20 \%$ USAP+MI, $13.33 \%$ asymptomatic patients). About $40 \%$ patients had neurological symptoms (20\% TIA, $13.33 \%$ Stroke, $6.66 \%$ TIA with stroke) and $9(60 \%)$ patients were free from neurological symptoms.
Table-1: Preoperative demographic variable

\begin{tabular}{|c|c|c|}
\hline \multicolumn{2}{|c|}{$\begin{array}{l}\text { Variables } \\
\text { Age }\end{array}$} & \multirow{2}{*}{$\begin{array}{c}\mathbf{n}=\mathbf{1 5} \\
62.5 \pm 2.8 \\
12(80 \%)\end{array}$} \\
\hline Sex & Male & \\
\hline & Female & $3(20 \%)$ \\
\hline \multirow[t]{5}{*}{ Risk factors } & Hypertension & $15(100 \%)$ \\
\hline & Smoking & $12(80 \%)$ \\
\hline & Dyslipidemia & $12(80 \%)$ \\
\hline & Diabetes mellitus & $9(60 \%)$ \\
\hline & MI & $6(40 \%)$ \\
\hline \multirow[t]{5}{*}{ Cardiac symptoms } & USAP & $4(26.66 \%)$ \\
\hline & USAP + MI & $3(20 \%)$ \\
\hline & Asymptomatic & $2(13.33 \%)$ \\
\hline & TIA & $3(20 \%)$ \\
\hline & Stroke & $2(13.33 \%)$ \\
\hline \multirow{3}{*}{$\begin{array}{l}\text { Neurological } \\
\text { symptoms }\end{array}$} & TIA + stroke & $1(6.66 \%)$ \\
\hline & Asymptomatic & $9(60 \%)$ \\
\hline & Ipsilateral stenosis & $82.5 \pm 5.5 \%$ \\
\hline
\end{tabular}

Table II shows severity of vascular lesion involving carotid artery and coronary artery. Majority 7 (46.66\%) patient have $75-90 \%$ Carotid artery stenosis. Five (33.33\%) patients were found Left main disease ( $>50 \%$ lesion) and $100 \%$ patients have had significant LAD lesion in this study. Twelve $(80 \%)$ patients show significant lesion in RCA and ten $(66.66 \%)$ patients had OM disease.

Table-2: Severity of Vascular lesion

\begin{tabular}{lcc}
\hline \multicolumn{2}{l}{ Severity of Vascular lesion } & $\mathbf{n = 1 5}$ \\
\hline Carotid & $50-75 \%$ & $5(33.33 \%)$ \\
artery stenosis & $75-90 \%$ & $7(46.66 \%)$ \\
& $>90 \%$ & $3(20 \%)$ \\
Coronary artery & LM Disease & $5(33.33 \%)$ \\
disease & $(>50 \%$ lesion $)$ & \\
$(>60 \%$ lesion) & LAD & $15(100 \%)$ \\
& Obtuse Marginal & $10(66.66 \%)$ \\
\hline
\end{tabular}

Table-3 shows that 6 patients experienced right (40\%), though $8(53.33 \%)$ experienced left and 1 (6.66\%) had respective CEA. Two (13.33\%) had a perioperative stroke while One of them had TIAs $(6.6 \%)$. One patients $(6.66 \%)$ experienced single, five $(33.33 \%)$ double vessel, and $9(60 \%)$ triple or more vessel involvement. 
AKMMC J $2018: 9(1)$

Table-3: Operative data

\begin{tabular}{lcc}
\hline \multicolumn{2}{c}{ Operation } & \multicolumn{1}{c}{$\mathbf{n = 1 5}$} \\
\hline CEA & Right & $6(40 \%)$ \\
& Left & $8(53.33 \%)$ \\
& Bilateral & $1(6.66 \%)$ \\
CABG & Single vessel & $1(6.66 \%)$ \\
& Double vessel & $5(33.33 \%)$ \\
& Triple vessel or more & $9(60 \%)$ \\
\hline
\end{tabular}

In our study postoperative outcome excellent. Mean ICU stay was $36.6 \pm 4.5 \mathrm{~h}$ and patients were released in 10 days. There was no mortality in the early postoperative period and co-morbidity was less significant $(6.6 \%$ myocardial ischemia, $13.33 \%$ Atrial fibrillation, $6.66 \%$ TIA, $13.33 \%$ Stroke). There were $1(6.66 \%)$ postoperative Acute renal failure was reported by serum Creatinine levels. Two (13.33\%) patients showed respiratory complications; $6.6 \%$ of them were for wound infection (Table-4).

Table-4: Postoperative Outcomes

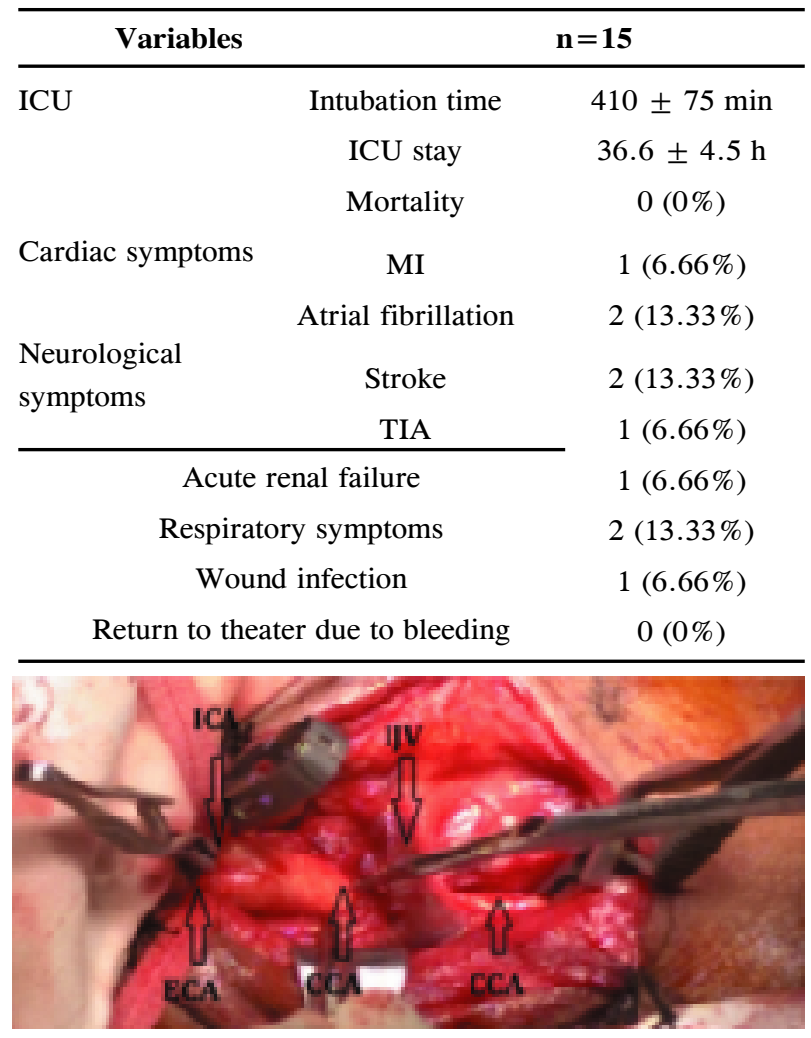

Figure-1: Neck incision showing common carotid artery (CCA), internal carotid artery (ICA), external carotid artery (ECA), and internal jugular vein (IJV).

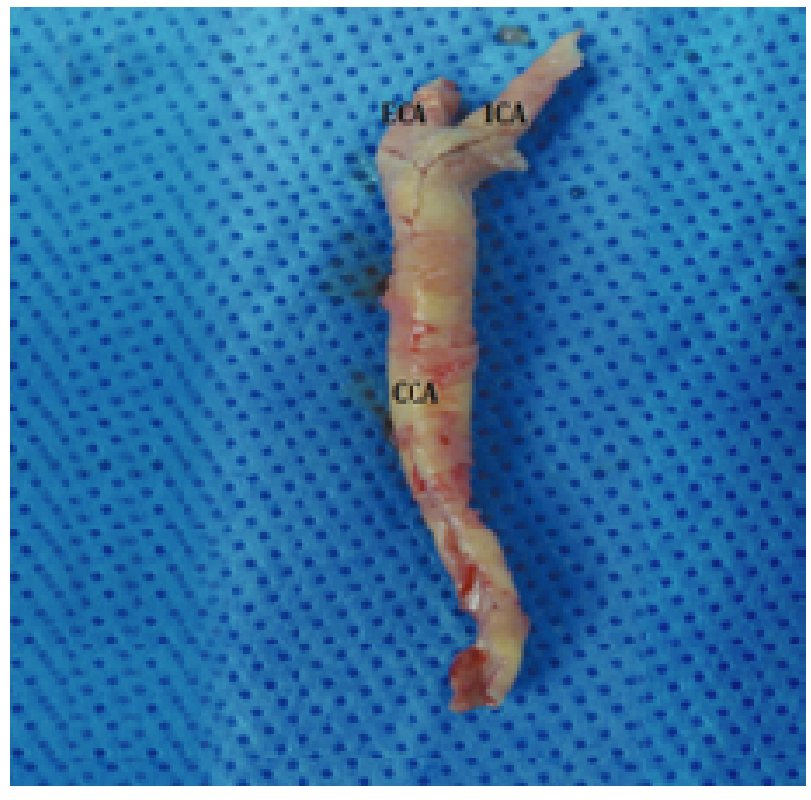

Figure-2: Carotid atheroma involving both internal and external carotid artery.

\section{Discussion}

The concurrent CEA-OPCABG procedure is typically performed to reduce the risk of cerebral injury and stroke. Cardiovascular disease is the leading cause of death worldwide and the importance of concurrent carotid and coronary disease has been recognized since the introduction of aorto-coronary bypass surgery, with the first series of combined CEA-CABG published in 1972. CEA is done to improve blood flow to brain and relieve the neurological symptoms of carotid artery stenosis and to prevent cerebral ischemia and infarction and consequent permanent neurological deficits. Patients with IHD are associated with 3$12 \%$ incidence of CAS. The presence of CAS increases the risk of stroke after CABG. ${ }^{1,2}$ CEA is the gold standard treatment for CAS3. Two Staged operation approach showed less morbidity and mortality because the surgical stress is divided into two parts with a time gap. ${ }^{4,5,6}$ But the symptoms of CAD or CAS will be present in the interval period and the patients with acute symptoms can't wait for two staged surgeries. But in combined surgery, there is low incidence of stroke, acute MI, mortality, and cost effective with single anesthesia and reduce hospitalization. ${ }^{7}$ Surgeons at present prefer CEA with off pump coronary bypass 
(OPCAB) in a single sitting, because of lo pressure circulation and high dose of heparin use during on pump CABG. Combined CEA with OPCABG is safe, effective, and with less neurological complication compared to combined (CEA+on pump CABG) and staged approach. For concurrent surgery (CEA + OPCABG) general anesthesia is preferred because of long duration of surgery, better cardio-pulmonary control and neuro-protection. Modern endovascular techniques e.g. stent/percutaneous transluminal angioplasty (PTA) may perform prior to $\mathrm{CABG}$ in high-risk patients like moribund condition, high up carotid stenosis, presence of neck wound. But the risks of mortality and morbidity are equivalent to CEA in symptomatic and asymptomatic patients. But the risk of incidence of thrombosis and re-stenosis is little more in patient with stent/PTA. ${ }^{8}$

A proceeding with discussion exists about the most suitable surgical choice for patients with coronary artery disease requiring surgery who additionally have noteworthy carotid artery disease. Approaches differ from thoroughly disregarding carotid artery stenosis at the season of myocardial revascularization, to performing organized operations, or directing the double operations with single anesthesia. ${ }^{9}$ Neurologic monitoring is an important safety measure for CEA. There are various methods of neurological monitoring like electroencephalography (EEG), somatosensoryevoked potential (SSEP), transcranial Doppler (TCD), ICA stump pressure, regional cerebral O2 saturation (rSO2), bispectral index (BIS). ${ }^{5}$ Detection of cerebral hypo-perfusion by any of these methods will guide for immediate placement of intraluminal shunt. BIS can provide more information regarding interactions between cortical and sub cortical neuronal generators and can correlates with clinical measures of hypnosis, sedation, reduced cerebral metabolic rate, and also cerebral hypo-perfusion. The presence of cerebral infarct and hypertension increase the perioperative neurologic risk. ${ }^{9}$ But we can't perform neurological monitoring due to our technical limitation. We surmise that when a specialist works on just a single disease at the season of surgery he or she will experience the unfavorable impacts of the other, at peri-operatively as well as postoperatively. Diverse creators have played out the consolidated approach like us as the system of decision in concurrent blood vessel illness to maintain a strategic distance from MI and lessen neurologic deficiencies. ${ }^{7,12}$

In a study of simultaneous surgery in 94 papers, in a total of 7863 procedures, Naylor et al. observed that the rates of stroke $4.6 \%$, AMI 3.6\%, and death $4.6 \%$. Analysis of results according to publication date (1972-1992 vs. 1993-2002), showed a decrease in death rate $(5.2 \%$ vs. $4.4 \%)$, stroke $(6.5 \%$ vs. $3.3 \%)$, and AMI $(4.3 \%$ vs. $3.4 \%) .{ }^{10}$ The postoperative consequences of our experience were $1(6.6 \%)$ MI, 2 (13.33\%) stroke, and 1 (6.6\%) TIA cases without any mortality. Borger et al. also arranged a meta-analysis utilizing the discoveries of 16 studies contrasting consolidated and organized techniques. Despite the fact that the consequences of the arranged methodology of this meta-analysis exhibited noteworthy abatements in the rates of the essential results of these reviews as they were stroke and mortality, there were likewise examines in the paper recommending joined systems to be the best decision in patients with concurrent carotid and coronary artery disease.Fichino et al. ${ }^{11}$ also reported their outcomes after combined surgery in thirty patients in Brazil. No perioperative AMI was found; two patients had post-operative TIA $(6.6 \%)$ and mortality rate was $(6.6 \%)$ due to stroke. There were 51 patients enduring stroke $(6.0 \%)$ while 40 of them were dead $(4.7 \%)$ from 844 patients that experienced a joined strategy. A critical optional end purpose of this paper was MI and $4.6 \%$ of the patients indicated MI. ${ }^{12}$

Meharwal et al. expressed that the benefits of combined CABG and CEA over the organized method were less introduction to anesthesia and cost-adequacy relying upon a shorter time of ventilatory support, and ICU and doctor's facility remain. Mean intubation time was $18 \mathrm{~h}$, emergency unit was $22 \mathrm{~h}$, and time of release time was 6.2 days in their review ${ }^{7}$, though mean intubation time was around 7 hours, ICU stay was 36.66 hours, and the hospital release time frame was 10 days in our study, exceptionally satisfactory outcomes. Following combined surgery, Mackey et al. also 
observed that mean duration of hospital stay was 10.3 to 16 days. ${ }^{13}$

Mishra et al. analyzed a gathering of 166 patients who experienced a consolidated strategy by OPCABG and CEA with 192 patients who experienced a joined methodology by ordinary CABG through CPB and CEA. ${ }^{14}$ Pre-, intra-, and postoperative discoveries of both gatherings were looked at and despite the fact that the OPCABG gathering's outcomes were better there were no factually huge contrasts between the gatherings however a portion of the useful impacts of OPCABG in these conceivably high hazard patients for perioperative neurologic antagonistic impacts were obviously experienced. The mix of OPCABG with CEA for patients with existing together carotid and coronary disease keeps away from $\mathrm{CPB}$ and shields the patients from stroke by disallowing nonpulsatile extracorporeal dissemination and its unfavorable impacts, for example, low stream marvels and irritation, and goes around the vast majority of the real hazard elements of stroke by means of partial aortic control with a consequence of a lessened danger of atheroembolism emerging from the aorta. The other hotspot for embolism is carotid supply routes and the hazard for carotid embolism is decreased by performing CEA before OPCABG in joined techniques. We also do that; first CEA followed by OPCABG.

In a study, Dylewski et al. shows the occurrence of co-morbidity following combined CEA with CABG which is similar to our findings. They found $12 \%$ respiratory complications, $6 \%$ acute kidney failure, $5 \%$ bleeding complication needs surgical reintervention, $4 \%$ wound infection, 33\% arrhythmias in their study population. ${ }^{15}$

In our study, significant common carotid artery stenosis with history of TIA and multi-vessel coronary artery disease with co-morbidity like DM and hypertension, necessitate combined surgery $(\mathrm{CEA}+\mathrm{CABG})$. Because the newer treatment modalities like endovascular stenting or PTCA has the chance of thrombosis, embolization, and stent migration. ${ }^{8}$ OPCABG surgery has less neurological morbidity. But on beating heart, the graft anastomosis in multi-vessel disease especially right coronary and circumflex artery may produce severe hemodynamic instability. ${ }^{16,17}$ For anesthesia, thiopentone along with fentanyl, norcuronium, isoflurane and lignocaine helped to blunt the hemodynamic response to intubation. ${ }^{18} \mathrm{We}$ used thiopentone, fentanyl and norcuronium for anesthesia. Thiopentone has the greatest protective effect against focal ischemia. Propofol affords early awakening of patient but may causes hypotension. Isoflurane produces dose related reduction in cerebral metabolic rate of $\mathrm{O} 2$ (CMRO2) with increase cerebral blood flow $(\mathrm{CBF})$. Hypotension was treated with infusion of inotropes e.g. dopamine. Mannitol was given before and after CEA to reduce intracranial pressure (ICP) and cerebral edema. Dexamethasone was used for its membrane stabilizing effect in neuroprotection. NTG and/or dopamine were used in regulated infusion to maintain stable blood pressure in peri-operative period.

\section{Conclusion}

Patients with coexisting CAS and CAD, concurrent CEA with OPCABG has been accepted as a standard of management at our institute. Combined approach will result in improve morbidity, single exposure to anesthesia, cost effectiveness and short duration of hospital stay. Maintenance of stable blood pressure (systolic BP $60-70 \mathrm{~mm} \mathrm{Hg}$ ) in the perioperative period is of prime importance and is mandatory for better cardiac and neurological outcome. But the question of management of the second carotid artery stenosis remains unanswered! Conflict of interest: We have no conflict of interest.

\section{Conflict of interest: None}

\section{References}

1. Snatulli G. Epidemiology of cardiovascular disease in the $21^{\text {st }}$ century: updated numbers and updated facts. JCvD 2013; 1:1-2.

2. Bernhard V.M., Johnson W.D., Peterson J.J. Carotid artery stenosis. Association with surgery for coronary artery disease. Arch Surg1972;105: 837-840.

3. Allain R., Marone L.K., Meltzer J., Jeyabalan G. Carotid endarterectomy. IntAnesthesiol Clin 2005; 43: 15-38. 
4. Antunes P. E., Anacleto G., Oliveira J.M.F. Staged carotid and coronary surgery for concomitant carotid and coronary artery disease. Eur J CardiothoracSurg 2002; 21: 181-186.

5. Trachiotis G. D., Pfister A.J. Management strategy for simultaneous carotid endartectomy and coronary revascularization. Ann ThoracSurg 1997; 64: 1013-1018.

6. Hill M.D., Shrive F.M., Kennedy J. Simultaneous carotid endarterectomy and coronary artery bypass surgery in Canada. Neurology 2005; 64: 1425-1437.

7. Meharwal Z.S., Mishra A., Trehan N. Safety and efficacy of one stage off-pump coronary artery operation and carotid endarterectomy. Ann ThoracSurg 2002; 73: 793-797.

8. Koebbe C.J., Liebman K., Venzedaroglu E., Rosenwasser R. The role of carotid angioplasty and stenting in carotid revascularization. Neurol Res 2005; 27: 53-58.

9. Duvan i., Gürbüz A., Demircin M. Evaluation of the performance of a carotid subclavian by-pass as a source for internal thoracic artery. Turk $\mathbf{J}$ Med Sci 2009; 39: 475-478.

10. Naylor R., Cuffe R.L., Rothwell P.M., et al A systematic review of outcome following synchronous carotid endarterectomy and coronary artery bypass: influence of surgical and patient variables. Eur J VascEndovascSurg 2003; 26: 230-241.

11. Fichino M.Z.S., Paulista P.P., Souza L.C.B. Endarterectomia e revascularizaçãosimultânea do miocárdio. Arq Bras Cardiol 1983; 41: 323326.
12. Borger M.A., Fremes S.F., Weisel R.D., et al. Coronary bypass and carotid endarterectomy: does a combined approach increase risk. A metaanalysis. Ann ThoracSurg 1999; 68: 1420.

13. Mackey W.C., Khabbaz K., Bojar R. Simultaneous carotid endarterectomy and coronary bypass: perioperative risk and longterm survival. J VascSurg 1996; 24: 58-64.

14. Mishra Y., Wasir H., Kohli V., et al. Concomitant carotid endarterectomy and coronary bypass surgery: outcome of on-pump and off-pump techniques. Ann ThoracSurg 2004; 78: 2037-2042.

15. Dylewski M., Canver C.C., Chanda J. Coronary artery bypass combined with bilateral carotid endarterectomy. Ann ThoracSurg 2001; 71: 777-782.

16. Gopaldas R.R., Chu D., Dao T.K. Staged versus synchronous carotid endarterectomy and coronary artery bypass grafting: analysis of 10year nationwide outcomes. Ann ThoracSurg 2011; 91: 1323-1329.

17. Prasad S.M., Li S., Rankin J.S. Current outcomes of simultaneous carotid endarterectomy and coronary artery bypass graft surgery in North America. World J Surg 2010; 34: 2292-2298.

18. ValderStarre P.J., Guta C. Choice of anesthetics. AnesthesiolClin N Am 2004; 22: 251-264. 